\title{
Study on the Operational Mechanism of Integrative Development of Producer Service Industry and Manufacturing Industry
}

\author{
Based on the Perspective of Knowledge Module
}

\author{
Yajun Wang \\ College of Economics and Management \\ Ningxia University \\ Yinchuan, China
}

\begin{abstract}
Knowledge has become the key production factor in modern industrial production. The production mode of manufacturing industry has changed from the traditional integration industrial chain form to the division of industry chain based on the module. The internal service function of manufacturing industry is also gradually strong and independent, and forms an emerging producer service industry and becomes the main growth point of modern economy. The support of information technology and learning platform is the technical basis for realizing the integration of producer service industry and manufacturing industry, and the construction, innovation, incentive and control of knowledge module are the core content of the integration. Based on the perspective of knowledge module, this paper studies the operation mechanism of the integrative development of producer service industry and manufacturing industry, analyzes its internal operating mechanism and then draws the corresponding conclusions.
\end{abstract}

Keywords-knowledge module; producer service industry; manufacturing industry; integrative development; operational mechanism

\section{INTRODUCTION}

The rapid development of information technology and communication network has changed the traditional industrial boundary and formed a new type of industry integration in the modern sense. Centered on the information technology revolution, the industrial revolution has changed the production mode of traditional industrialization and made the production of modern industrialization based on customer oriented and the product service based on the customized, intelligent, information and knowledge. In the industrial field of modern industrialization, the advanced manufacturing industry has gradually moved towards the trend of service, and the modern service industry has gradually converted to the industrialized operation. The producer services in modern service industry have become the most important part of service value-added, and the boundaries between the producer services and manufacturing industry are becoming increasingly blurred, and the integration trend of the two industries is further strengthened. Porter (1985) is a proponent of the "fusion theory" of manufacturing and services, and he believes that information and knowledge is the "adhesive" for the integration of manufacturing and services. The information technology enterprises are integrated into the modern industrial system, and the old economy accepts the new information technology transformation, and then the original industry develops from the direction of single industry to the mixed industry. As we can see, through the continuous promotion of information resources, speed up the interaction between products and services, dilute the boundaries between manufacturing industry and service industry and bring the proliferation of product value itself, and information technology has become a booster to promote the integration of manufacturing and service. In the modern producer service industry, the intensive distribution and effective connection of knowledge has externalized the internal division of labor in the original manufacturing industry, which has become a new pattern industry based on knowledge diffusion and innovation, realizing economies of scale and obtaining abundant scale returns. This is not only the result of specialization and modular division, but also the result of separating service from the manufacturing industry.

\section{THE OPERATIONAL MECHANISM OF INDUSTRY INTEGRATION FROM THE PERSPECTIVE OF KNOWLEDGE MODULE}

The premise of the integrative development of industrialization lies in the construction and embedding of the knowledge module of integration of producer service industry (the core component of modern service industry) and manufacturing industry. The highly specialized knowledge of modern service industry determines the further division of labor within the manufacturing industry and the further expansion of market. The producer service industry continuously separates the service module from the interior of manufacturing and uses highly skilled specialized knowledge to make this kind of division of labor promote the reintegration of industry, and expands the trend of fuzzy boundaries between the producer service industry and manufacturing industry. This kind of knowledge-intensive inherent attribute 
of producer service industry is gradually formed with the development of information technology. In the process of rapid development of knowledge-intensive service industry, the most outstanding performance is the link and integration of knowledge-intensive industry, such as information technology, finance, technology and trade, financing services and so on. Machlup (1962) thought that as knowledge-intensive industry, the productive service industry is not only the industry which can provide with strong professional knowledge of assets, but also the industry that needs professional knowledge. Some scholars have defined the producer service industry as business services with specialized human capital and intellectual capital. In the research and development, marketing and other service modules, the producer service industry reflects the organization and construction of knowledge and coordinates with manufacturing enterprises and forms a new knowledge system by the knowledge community. In the media function of knowledge, manufacturing and service can realize the fuzzy boundaries. At the same time, the service function of products of manufacturing itself also manifests incisively and vividly. Manufacturing industry uses intangible knowledge services to enhance the competitiveness of enterprises, which mainly represents the servitization in the process of input and output. The servitization in the process of input is based on the advantage of information technology to transmit the knowledge and information identification to consumers, in order to increase the added value of enterprise output. And servitization in the process of output strips out the products of business center of many manufacturing enterprises. In view of manpower, financial resources and other costs and creating greater profit margins, manufacturing enterprises will implement the service module outsourcing or their own transformation, and gradually break away from the manufacturing and organization module production of low cost, turn to provide research and development and fund management service module production, and gradually become the professional service enterprises in the process of evolution. The integration of manufacturing industry and producer service industry is realized through the embedding of knowledge modules. Because the essence of integration of producer service industry and manufacturing industry is the integration of information and knowledge, and a complete knowledge module is formed after the integration. After the integration, the knowledge modules are widely integrated into the industries through the technical support based on the knowledge diffusion network, knowledge circulation flow and knowledge chain. In the process of internal servitization and external module outsourcing of manufacturing industry, research and development and design will use knowledge to create, form the inherent knowledge module, play the role of value function of knowledge module in the producer service industry and incorporate it into the manufacturing industry. Thus, it can realize the construction and embedding of the knowledge module of integration of producer service industry and manufacturing industry.

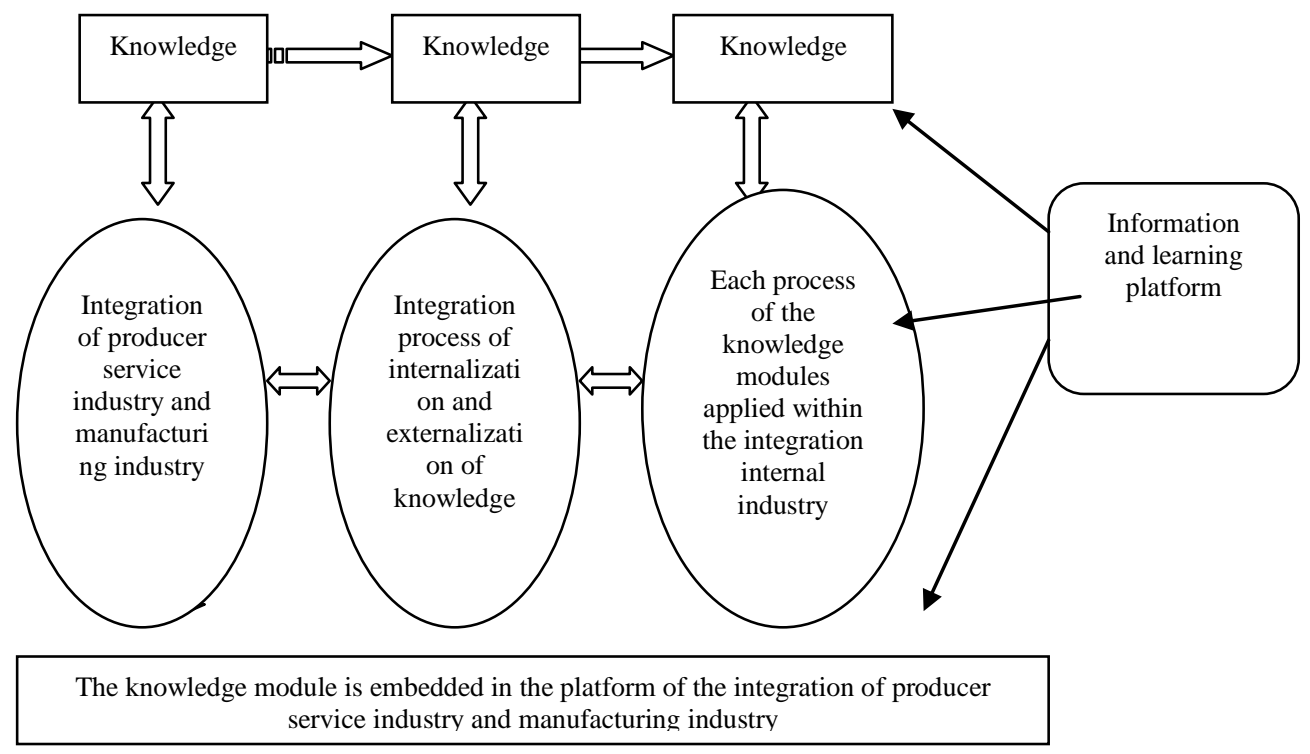

Fig. 1. The imbedding of knowledge module in the process of integration of producer service industry and manufacturing industry.

As shown in "Fig. 1", the knowledge module integrates all kinds of specialized knowledge, outsources the service platform of special information technology to the research and development enterprises and penetrates itself onto each platform of enterprises which can make the imbedding effect of knowledge module reach to its maximization and highlight the role of knowledge modules in industry integration. Use knowledge innovation to effectively convert knowledge, a. Data sources: drawn by the author highlight the process of externalization and internalization and keep the innovation and application of knowledge. However, the penetration of knowledge module can realize the integration of knowledge module through the module imbedding of information in each department of producer service industry and manufacturing industry, such as employees, customers, management and process operation. 
The effective and timely embedding of knowledge modules is the operating mechanism of the integrative development of producer service industry and manufacturing industry. Knowledge itself is intangible, and its use has certain nonexcludability. In view of its special nature, its common use with many resources should be differentiated. As the media function, the knowledge module has the function of communication and the bridge for the integration and development. Therefore, the integrative development of producer service industry and manufacturing industry can not be separated from the extensive application of knowledge modules. The increasing property of knowledge reward and the nature of cost payment in the process of transfer and dissemination determine that it needs to provide a platform for mutual learning in the process of integration of producer service industry and manufacturing industry. This leads to the interaction of knowledge. However, the communication and learning of knowledge in different subjects is also the diffusion and communication process of knowledge module in the whole process, which also can stimulate the subjects to make conversion and innovation of the knowledge performance. Different subjects have different mastery degree for knowledge module, which can also stimulate the interpersonal communication and interactive learning. In the process of penetration service of knowledge module, this exchange increases the knowledge content of the organization's internal bodies and members and improves the comprehensive competitiveness of the industry after the integration. As shown in "Fig. 2":

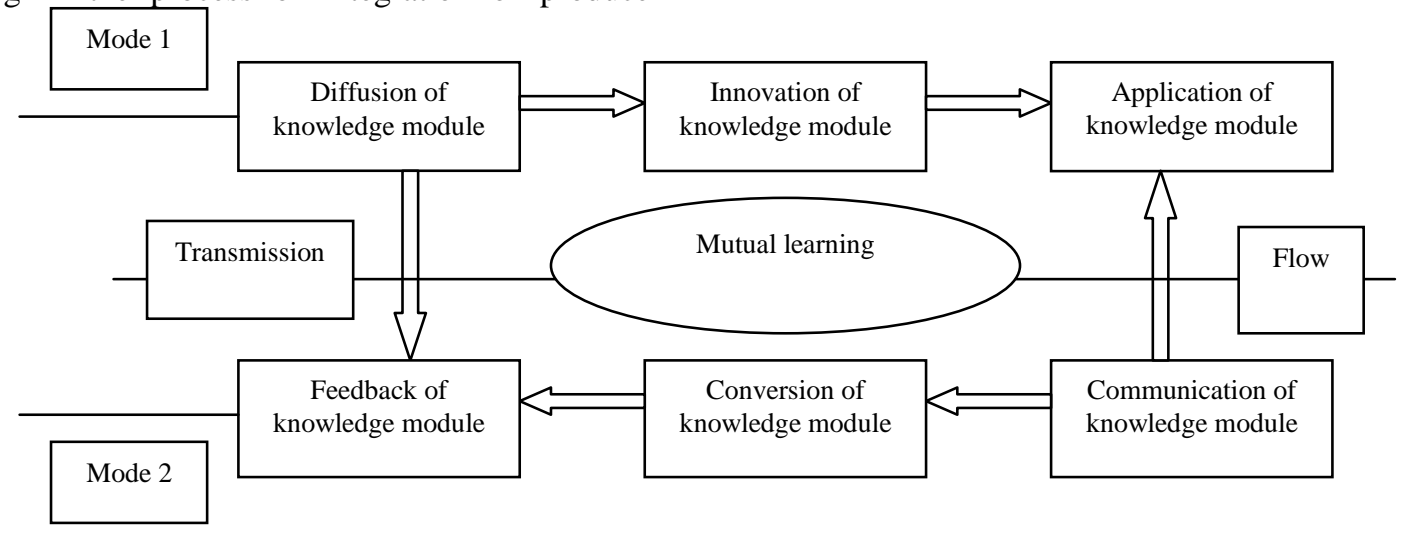

Fig. 2. The operation process of internal knowledge module of integrative development of producer service industry and manufacturing industry.

Thus it can be seen that the movement of knowledge modules is a powerful weapon for the integration of producer service industry and manufacturing industry. On the platform of interactive learning of knowledge modules, it is a process that uses various knowledge to transmit knowledge module. This process consists of two modes: one is to synthesize various types of knowledge by establishing knowledge base and realize the diffusion of knowledge modules and the communication of producer service industry and manufacturing industry. In this mode, the platform of the knowledge module is transmitted through various ways, so as to realize the absorption for these knowledge modules. In the process of communication, we can find out the new knowledge module which can be innovative, and refit and re-apply it, and use the knowledge module in different angles. In the process of communication of knowledge module, another way is to carry out some effective screening and filtration for some knowledge modules, properly convert the tacit knowledge and explicit knowledge of knowledge module, and timely review the application functions of these modules and timely feedback the information and knowledge update to the integration system. In theory, the operation of knowledge module consists of two independent ways. But in practice, these two methods are parallel and not completely split, but they are interacted with each other. The operational process of knowledge module is the internal manifestation of the integrative development of producer service industry and manufacturing industry. And
${ }^{\text {b. }}$ Data sources: drawn by the author knowledge itself serves as a unit and a medium which can build a bridge to the road of integration. The specific modes of operation are mainly shown in the following aspects:

First, it is the communication and diffusion of knowledge module. The communication of knowledge module needs to build a learning platform between the subjects. Through the platform, we can determine the key knowledge needed in the interior of integration system, look up and screen this knowledge to conform the knowledge which is identical to the internal demand of system, and then use the inertial instructions in the system to assemble this filtered knowledge, relocate, pack and transform it into the needed knowledge of integration system.

Second, carry out the reasonable conversion and innovation for knowledge module. Within the system, the knowledge module is packed and converted into internal knowledge, which can manifest in two aspects of internalization and externalization. It can transform the explicit content and implicit content of the knowledge module between subjects. However, in the process of transformation and communication, it includes the domination of tacit knowledge and recessivation of explicit knowledge. Among them, domination of tacit knowledge is a process of tacit knowledge grouping which includes the integration of knowledge modules, and domination of tacit knowledge is beneficial to share knowledge modules. However, the recessivation of explicit 
knowledge is to constantly enlarge the value of knowledge itself through learning by different subjects. Therefore, the transformation process from explicit knowledge to tacit knowledge is the internalization of knowledge, which is an important way of knowledge elicitation, subject learning and the use of knowledge. The externalization of tacit knowledge constantly enriches the explicit knowledge base of the knowledge subject, and the organized explicit knowledge is the soil of tacit knowledge. They are mutually transformed and constantly circulating, and a large number of orderly virtuous circularly promotes the spiral promotion of knowledge chain integration and innovation ability.

Third, apply the knowledge module on feedback. Feedback is to transmit the other processes in the process of transmission to the whole internal integration system by way of using new knowledge module. In this way, other members can analyze the new knowledge module by learning, apply the positive or negative module to the interior of new knowledge, conduct feedback continually and realize the circulating of the process. Making full use of feedback is conducive to acquire all aspects of knowledge in knowledge resources, and constantly participate in the internal learning of the integration system, and coordinate the knowledge stock among the members of the knowledge module, and maximize the embedded knowledge module.

\section{CONCLUSION}

Taken together, the operation of integration of producer service industry and manufacturing industry based on the knowledge module is a complex process. This process is based on the movement of the knowledge module and the mutual learning of members within the system. From the embedding of knowledge modules to the integration and interaction between producer service industry and manufacturing industry, the whole process is to compress knowledge into a small subsystem. Make use of the function of plug and play of module to realize the process of knowledge sharing, learning, information technology support and feedback. Therefore, the process of the integration of producer service industry and manufacturing industry is also the process of embedding and integration of knowledge module. The knowledge module embedding mechanism includes the construction, innovation, incentive, control of knowledge module itself and the support of information technology and learning platform and so on. Among them, the support of information technology and learning platform is the technical base for realizing the integration of producer service industry and manufacturing industry. The construction, innovation, incentive and control of knowledge modules are the core content of the integration. In this integration mechanism, the accumulation and integration of knowledge modules can be realized in order to guarantee the transformation between explicit information and implicit information in the knowledge module as shown in "Fig. 3":

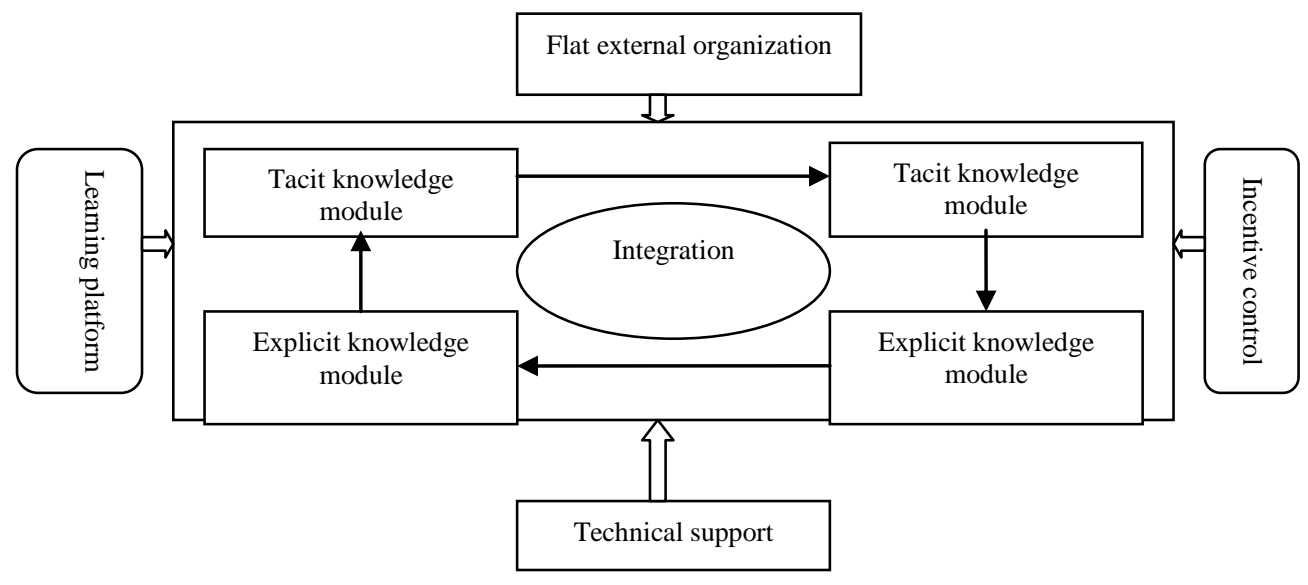

Fig. 3. The integration mechanism of producer service industry and manufacturing industry based on knowledge module

In order to realize that the above knowledge modules can be flexibly embedded in the process of integrative development of producer service industry and manufacturing industry, knowledge modules must be based on the scientific and reasonable organizational structure inside the enterprise. There are many enterprise organization patterns, and among them, the flat organizational pattern is the organization pattern of modern enterprise. Compared with the traditional vertical integration organization structure, it has more flexible and sensitive characteristics. However, the flat organizational structure is more adapted to the communication and exchange of knowledge module, by using the support of modern information, the organizational structure is more inclined to the
Data sources: drawn by the author branch structure of center construction and network, jointly accelerates the integration and diffusion of knowledge module, and improves the office efficiency of modern enterprise. At the same time, the flat organizational structure is also a virtual structure. Producer service enterprises and manufacturing enterprises use the alliance and cooperation of network type between modern enterprises, through knowledge and information, use data to communicate and exchange information, share the network design, and promote the optimal allocation of resources. The internal customers, suppliers and subcontractor of enterprises also use mutual learning and communication to achieve the sharing of resources within the organization, transform knowledge and 
information into the form of "learning and creating", constantly exchange and practice and gain the new knowledge of the outside world.

\section{REFERENCES}

[1] Morelli, N. (2002) Designing Product/Service Systems: A Methodological Exploration. DesignIssues 18, 3-17.

[2] Porter, M. and Ketels, C. (2003) UK Competitiveness: Moving to the Next Stage. London:Department of Trade and Industry.

[3] Langlois,R.N.,2000 :Modularity in technology and organization,Journal of Economic Behavior \&Organization VOL.49.

[4] Saxenian,A(2001) :The Silicon Valley-Hsinchu Connection :Technical Communities and Industrial Upgrading,Berkeley Planning Journal 15(2001): 3.31

[5] Yan Xingyu, Gao Juemin. A reexamination of Modularity Theory: Limitations and Scope of Application[J]. China Industry Economy, 2007, (4).

[6] Fan Aijun, Yan Li. Influence of Modularity on the Evolution of Division of Labor:An Interpretation Based on Becker-Murphy Model[J]. China Industry Economy, 2006, (12).

[7] Xu Hongling, Li Shuanghai. The Evolution of Value Chain's Form and Modular Organization Coordinating[J]. China Industry Economy, 2005, (11).

[8] Li Haijian, Nie Huihua. Amalgamation of the Firm and the Market[J]. China Industry Economy, 2004, (8).

[9] Zhou Zhenhua. Informative Process and Industrial Crowd Expansion in the Industrial Convergence. Reform, 2004, (4).

[10] Tong Shizhong. Design Method and Application of Module Principle[M]. Beijing: Standards Press of China, 2000. 